\title{
A case for co-construction with teachers in curricular reform: Introducing computer science in primary school
}

\author{
Laila El-Hamamsy \\ laila.elhamamsy@epfl.ch \\ MOBOTS Group, EPFL \\ LEARN, EPFL \\ Lausanne, Switzerland \\ Morgane Chevalier \\ morgane.chevalier@epfl.ch \\ University of Teacher Education \\ Lausanne, Switzerland
}

\author{
Barbara Bruno \\ barbara.bruno@epfl.ch \\ CHILI Lab, EPFL \\ Lausanne, Switzerland
}

\author{
Jessica Dehler Zufferey \\ jessica.dehlerzufferey@epfl.ch \\ LEARN, EPFL \\ Lausanne, Switzerland
}

\author{
Helena Kovacs \\ helena.kovacs@epfl.ch \\ LEARN, EPFL \\ Lausanne, Switzerland
}
Francesco Mondada
francesco.mondada@epfl.ch
MOBOTS Group, EPFL
LEARN, EPFL
Lausanne, Switzerland

\begin{abstract}
With the introduction of Computer Science (CS) into curricula worldwide, researchers have investigated whether CS could be introduced transversally, as a support other disciplines. Few however consider both student learning and the teachers' perspective in their assessments. In a co-constructive approach to translational research, we collaborated with teachers, in two case studies involving two classes each, to investigate how CS content could be used transversally. More specifically, teacher inputs and student learning data were combined in a mixed methods analysis to determine whether two CS Unplugged (CSU) activities from the curriculum could be leveraged to teach disciplinary content in primary school. The findings indicated that the CSU activities could be leveraged for maths and spelling, but require validation at a larger scale. More important, though, are the takeaways of the co-constructive experience with teachers. Interestingly the benefits of co-construction went both ways. While researchers gained a deeper understanding of the effectiveness of the activities, teachers i) appreciated having detailed student learning analyses, devoid of biases and impressions, ii) changed their perspective about researchers, and iii) were open to other collaborative research initiatives which they found to be drivers of change and innovation in their practice. The way co-construction was approached also impacted the teachers' perception of their experience. Indeed, while one study was researcher-driven and included teachers, the other was teacherdriven and included researchers. When teacher-driven, the teachers felt they had a more active role, thus reflecting more on the study design, results and implications. Provided the positive impact that co-construction may have on innovation in teacher practices, different co-construction modalities must be investigated, as well as their implications on all stakeholders, including researchers.
\end{abstract}

Permission to make digital or hard copies of part or all of this work for personal or classroom use is granted without fee provided that copies are not made or distributed for profit or commercial advantage and that copies bear this notice and the full citation on the first page. Copyrights for third-party components of this work must be honored For all other uses, contact the owner/author(s).

ACE '22, February 14-18, 2022, Virtual Event, Australia

(c) 2022 Copyright held by the owner/author(s).

ACM ISBN 978-1-4503-9643-1/22/02.

https://doi.org/10.1145/3511861.3511883

\section{CCS CONCEPTS}

- Social and professional topics $\rightarrow$ K-12 education; Model curricula; • Applied computing $\rightarrow$ Education.

\section{KEYWORDS}

Computer science education, primary school, computer science unplugged, transversal integration, co-construction, translational research.

\section{ACM Reference Format:}

Laila El-Hamamsy, Barbara Bruno, Helena Kovacs, Morgane Chevalier, Jessica Dehler Zufferey, and Francesco Mondada. 2022. A case for coconstruction with teachers in curricular reform: Introducing computer science in primary school. In Australasian Computing Education Conference (ACE '22), February 14-18, 2022, Virtual Event, Australia. ACM, New York, NY, USA, 10 pages. https://doi.org/10.1145/3511861.3511883

\section{INTRODUCTION}

Whenever a new discipline is introduced in the curriculum, a point of contention appears: is it possible to introduce the new content without taking time away from other elements in the curriculum? This conundrum is particularly relevant in the case of Computer Science (CS) in primary school, which is the target of a number of curricular reforms worldwide [19]. With primary school teaching being inherently transversal, many argue that CS content introduced at this level should be transversal too [19]. This transversality can be achieved either by using CS content as a support for other disciplines [34, 48] or by contributing to the development of transversal competencies. The above principle has motivated numerous researchers to investigate how CS, or Educational Robotics (often used as a medium to teach CS [16]) can be leveraged in various disciplinary contexts $[8,20,32]$ such as maths $[4,7,8,25,48]$, sciences $[38,48]$, languages [42], or in the context of transversal skills such as creativity [50] and problem solving [10]. To the authors' knowledge, few have considered the teachers' perspective in such endeavours $[9,20,31,48,50]$. Some researchers even explicitly mention their lack of experience in formal pedagogical and educational theories [8] as limitations of their studies. Even less studies present analyses which include the results of student assessments and the 
teachers' perspective of the content and of student learning $[26,31]$.

The lack of teacher involvement is potentially problematic, notably in contexts of translational research ${ }^{1}$ [21]. In the context of CS curricular reform, effective translational research is also complex to achieve as the discipline is often met with reticence and little adoption into teacher practices [39, 45]. Numerous numerous barriers, both internal and external [18], are often evoked and appear to stem from the limited involvement of teachers in the process. Multiple sources thus stress the importance of collaboration among all stakeholders, including teachers, in research practice partnerships [41] and curricular reforms [6,12,13,17], as a necessary condition for the success of such endeavours. The exclusion of teachers from curricular reform processes appears even more surprising when considering that :

- teachers have "localised knowledge of their students [...] and can provide unique, on-the-ground insight into the enactment of specific curriculum materials" [14],

- teachers are the experts who are best suited to reflect on the feasibility of such projects in classrooms [17],

- "creators of computing curricula do not always have formal pedagogical training" [8, p.1], and while helping them understand and follow best pedagogical practices can address some of the limits of computing education [8], this is not always sufficient.

We consider that teachers, as the end users of the devised curricular content, play a pivotal role in curricular reform, which no alternative to their inclusion can match. Teachers must not only be trained in order to successfully integrate computing curricula in $\mathrm{K}-12$ [17, 45, 47], but they must also be actively engaged in the process [1]. Teachers not only provide hands-on pedagogical expertise, but are also the ones who ultimately decide whether or not to introduce a given content into their practices (i.e. adopt), and their perspective should be integrated from the start. Indeed, recent studies have demonstrated the benefits of co-construction (defined as the joint creation of knowledge and or practice ${ }^{2}$ ) for lesson units [12, 23, 26, 27, 37, 49] which, when following an appropriate model, promotes the adoption of the devised content into teacher practices [26]. This is also the case for CS curricular reforms that engage teachers in a co-constructive process $[5,6,17]$ and appear to contribute to teachers adopting the new content in the short and long term [17].

In this article, we discuss two cases of co-construction (one researcher-initiated, and one teacher-initiated) aiming at introducing CS concepts within other disciplines (namely, mathematics and french) through two CS Unplugged (CSU) activities [2, 3] (defined as activities that teach CS concepts without screens) at the primary school level. Specifically, we investigate the following research questions:

- RQ1. How do CS Unplugged activities contribute to learning in other disciplines?

\footnotetext{
${ }^{1}$ Translational research is a systematic approach to develop innovation by transforming research results into practical applications, but rarely applied in education [21]

${ }^{2} \mathrm{Co}$-construction is also referred to as co-creation and co-design in certain contexts
}

- RQ2. To what extent are the teacher's and researcher's assessments complementing each other?

- RQ3. Does the established teacher-researcher relationship contribute to a change in the teachers' perception of i) the content, ii) the researcher, and iii) translational research?

Concretely, RQ1 investigates the transversal quality of CS content, while RQ2 and RQ3 expand on the role of co-construction between researchers and teachers in translational research for CS curricular reform

\section{METHODOLOGY}

The case studies reported in this article are based on two popular CSU activities [3] for grades 1-4 (ages 5-9) from our regional CS curricular reform [16, 17]: the robot game [40] and the sorting machine [2].

Each case study involved one grade 3 and one grade 4 class (students aged 7-9) and their respective in-service teachers with a researcher present to observe the sessions. The teachers that participated in the studies had completed the mandatory regional CS continuing professional development program headed by the department of education the previous year $[16,17]$. This involved 4 days of CS-related teacher training which targeted concepts of algorithms \& programming, machines \& networks, and information $\&$ data. The program presented ready to use activities which combined different instruction modalities (i.e. using a combination of unplugged and plugged, robotic and non robotics activities) $[16,17]$.

The two case studies differ in i) the activities which were selected because they were the ones most adopted by teachers in the digital education reform for grades 1 to 4 , ii) the associated standard discipline (RQ1), and iii) the instigator of the collaboration (with one case study being designed by researchers who then sought the involvement of teachers and the other being designed by teachers who then sought the involvement of researchers). These case studies thus provide insight into how research can be co-constructed between researchers and teachers and the effects of the established teacher-researcher relationship (RQ2, RQ3).

To evaluate RQ1 and RQ2, we conducted a mixed methods analysis which includes 1) quantitative data on student learning and 2) qualitative data pertaining to the teachers' perception of the activity and its role in the curriculum, acquired through semi-structured interviews. RQ3 relies solely on the teacher interviews.

\subsection{The researcher-initiated case study: the robot game to teach mathematics concepts}

Many mathematics activities in grades 3 and 4 (students aged 7-9) seek to develop students' spatial abilities and grid-related concepts. This is also the case of certain activities from the new CS curriculum [17]. One of the most popular activities of said curriculum is the robot game [40]. The researchers, having reason to believe the activity could foster mathematics concepts that were part of the standard curriculum, designed the study and approached teachers that had followed the recent CS teacher training to run the study in their classroom. 


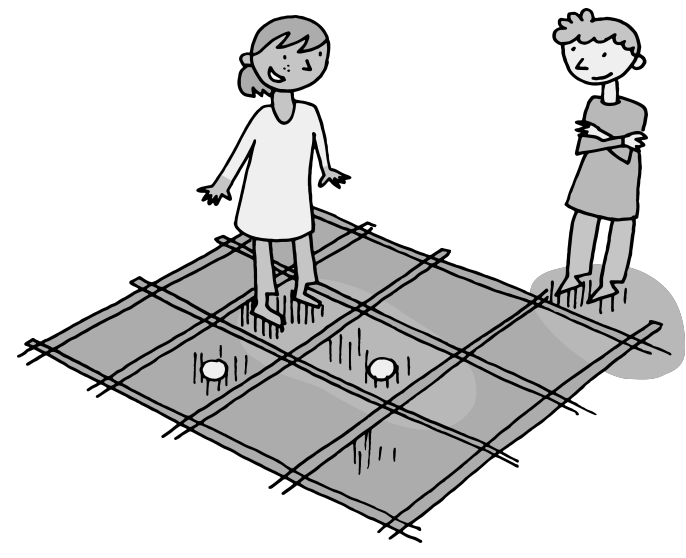

Figure 1: Illustration of the robot game (taken from the standard curriculum ${ }^{3}$ )

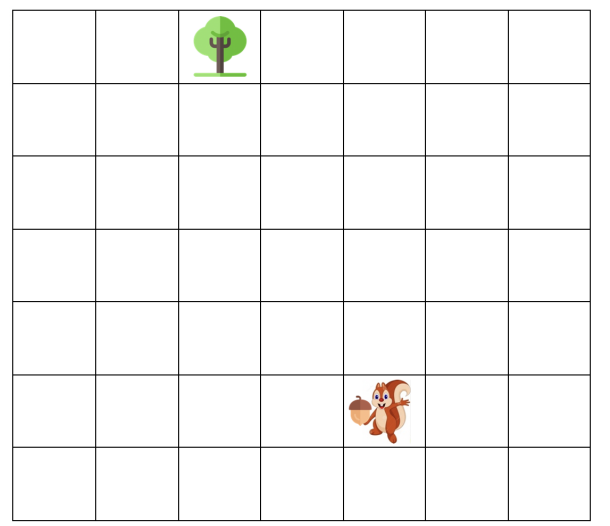

Figure 2: Exercise used to evaluate the acquisition of gridrelated concepts for the robot game, with the following instructions "Help the squirrel take its nut to the tree. Be careful, you shouldn't write anything on the grid!"

2.1.1 Description of the activity. The robot game g $^{3}$ is a two-hour collaborative grid-based CSU activity where students must help someone in the role of the "stupid robot" navigate on a floor mat with a grid illustrated on it (see Fig. 1) to pick up an object while avoiding obstacles. The activity is designed to kinaesthetically initiate students to the basics of algorithmics and CS concepts [16, 40], all the while training the students' spatial abilities. During the activity, students must work in teams and alternate between the role of the robot (i.e. executing orders), the role of the computer (i.e. giving orders to move the robot to a target location), and the role of the verifier (i.e. checking whether the robot has correctly executed the given instructions). Success in the activity thus relies on the students' ability to invent and agree on a univocal programming language, adapting to the constraints placed by the teacher (e.g. the robot is blind, deaf, or both).

${ }^{3}$ See DECODAGE - Education numérique - Version transitoire 2021 - 2022 - CC BY NC SA 4.0 - DFJC - DGEO 2021
2.1.2 Participants. Two voluntary generalist teachers (i.e. that teach all subjects), one from grade 3 and one grade 4, responded to an open call in their schools and were provided a detailed description of the activity and asked to introduce it into their respective classes. The teachers were informed that they could adapt the CS activity as they would do for any other activity that they would teach. Overall, 43 students (22 from grade 3 and 21 from grade 4 ) participated in the study.

2.1.3 Data Collection. A paper-based grid exercise (see Fig. 2) was administered as a pre-post test to evaluate learning of grid-related concepts. In the test, students have to help a squirrel take the hazelnut to the tree, without marking anything on the grid. The solutions were simultaneously annotated by two researchers using the following criteria, each normalised to obtain a score between 0 (min) and 1 (max), before summing to create a global performance metric:

- Abstraction of the grid, i.e. how did the students indicate the path without writing on the grid? (7 level ranking - 0 = did nothing, 1 = went around the grid, 2 = incorrect full grid reproduction, 3 = incorrect partial grid reproduction, $4=$ correct full grid reproduction, $5=$ correct partial grid reproduction, $6=$ did not need to reproduce the grid).

- Path coding strategy, i.e. how were the instructions encoded? (8 level ranking $-0=$ did nothing, $1=$ random drawing or sentence, 2 = path-related drawing or sentence, 3 = points connected by a line, $4=$ custom code, $5=$ explicit keywords, 6 = arrows mimicking the path's motion, 7 = aligned arrows).

- Notion of sequence, i.e. did the indicated path have a notion of sequence of steps? $(0=$ no, $1=$ yes $)$.

- Notion of distance, i.e. did the path indicate the distance to be travelled? $(0=$ no, $1=$ partially, $2=$ yes $)$

\subsection{The teacher-initiated case study: the sorting machine to teach spelling}

After participating in the first case study, the grade 4 teacher, who is invested in the establishments' CS curricular reform, was interested in continuing to investigate the benefits of the new CS activities being introduced in the curriculum. They hypothesised that a CSU activity, the sorting machine [2], could be leveraged as a complementary activity to help students practice their spelling. They also believed it was a fun alternative which would help students practice spelling without being encumbered by graphomotor difficulties. They involved colleagues in the experiments and researchers in the analyses to test their hypothesis. In itself, the teacher-initiated case study is a first result of co-construction by demonstrating how it can impact teacher practices and open avenues for collaborative translational research in the field.

2.2.1 Description of the activity. The sorting machine is a one hour kinaesthetic CSU activity [2] initially designed to teach participants how computers sort data in parallel (see Fig. 3). For younger students, while the emphasis may not be on understanding parallel sorting mechanisms per se, this activity is used to teach them to iteratively apply the if-else rule with objects of different types (e.g. numbers, objects, parts of a story etc...) according to predefined values (e.g. value, size or weight, order in the story) and conditional 


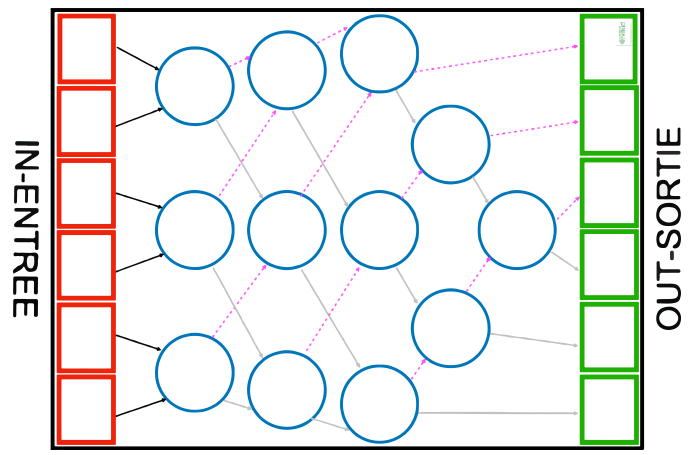

Figure 3: Illustration of the sorting machine network that the students enter on the left, iteratively compare objects to decide in which direction to move, and exit on the right.

rule (e.g. if superior go left, else right). Using a floor mat with a network illustrated on it (see Fig. 3 for a 6-input network), participants enter the network on one end (red squares) with a randomly attributed object in hand. They recursively compare their object with the ones of other participants when in a blue circle to determine in which direction to go (left or right as illustrated in Fig. 3), until the end of the network is reached (green squares), where the objects are sorted [16]. In the case of spelling, letters of selected words (of length 6 or more) are split into 6 parts and given to students to compare with respect to the order in the word. Success in the activity relies on adequately sorting the letters in the word.

The teachers believed that, unlike traditional approaches, the sorting machine forces students to split the words into letters and think about them individually compared to other activities where the word might be broken up into sounds, which in French can lead to numerous mistakes.

2.2.2 Participants and data collection. One grade 3 and the grade 4 generalist teacher from the first case study ran the experiments in their classrooms with 35 students (18 grade 4, and 17 grade 3 students). They selected a thematic set of 6 French Christmas themed words (5 of length 6, 1 of length $8^{4}$, see Fig. 4) which they practised during the activity and evaluated in a pre-post spelling test to assess progress on said words. Overall, 22 students (4 from grade 3, 18 from grade 4) were present for both the pre- and post-tests. While the teachers did a quick overview of the pre-post tests to see whether the students corrected errors related to complex sounds in the language and word-specific difficulties, the researchers adopted a more mathematical approach to the analysis. Using the Levenshtein distance (i.e. the minimal number of edits required to change one word into another), the proportion of spelling errors made was computed and normalised with respect to the word's length (max number of errors possible).

\subsection{Teacher Interviews}

2.3.1 Participants. Teachers from both case studies were interviewed by the researcher who participated in the two case studies to get their perspective on the CSU activities, on the results from

\footnotetext{
${ }^{4}$ The Christmas themed words: "bonnet", "bougie", "étoile", "emballer", "jouets", "lutins"
}

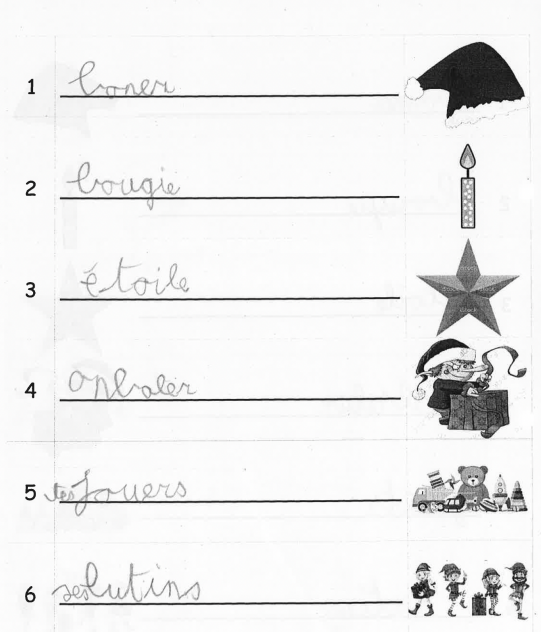

Figure 4: Pre- post- spelling test used to assess progress on the set of words practised with the sorting machine

the analysis of student learning, and on their co-construction experience. The interviews for the robot-game were conducted with both teachers. Please notice that the sorting-machine interviews only involved the grade 4 teacher, who was present with the grade 3 teacher and students during the session, and debriefed with the grade 3 teacher prior to the interview.

2.3.2 Semi-structured interview guide. The interviews were conducted using a semi-structured interview guide organised in four distinct parts.

The opening questions intended to explore the objectives and expectations of the interviewees, followed by a description of their experience during the activities:

(1) What was your objective when you decided to conduct the activity?

(2) What were your expectations?

(3) What metrics were of interest for you?

(4) Can you describe how the activities went?

The second part asked teachers to reflect on the students and student learning, as well as on the benefits and bottlenecks of the CS activities with regards to the interviewees' teaching practice:

(1) How do you think the activity impacted the students' maths / spelling skills?

(2) What other skills do you think may have been impacted?

(3) Do you see any benefits of doing the activity?

(4) Were there drawbacks?

(5) How do you perceive the activity with respect to others in the curriculum?

(6) Are / were there challenges to integrating the activity into your practice?

The third part of the interview included a presentation of the results of the pre-post test analysis conducted by the researcher and a discussion with the individual interviewee regarding what 
the results mean, in terms of their expectations, observations and prior experiences with the students. Following this discussion, a synthesis of the results was elaborated considering what both parties saw as the main takeaways from the experiment, and the teachers were asked whether they saw any benefit to having this parallel analysis.

At the end, the interviewees were asked about their opinions on co-construction and translational research, in the sense of what they perceived as their role in the research, as well as how they felt about the relationship with the researcher in this particular setting:

(1) How do you perceive the role research can play for teachers?

(2) How do you perceive the relationship between yourself and the researchers?

(3) How did you find this initiative?

2.3.3 Qualitative data analysis. The interviews were analysed using an inductive approach based on handwritten notes and transcribed audio recordings. Codes were grouped under two categories, with their own themes, that supplemented the analysis and discussion of the results. The first category relates to the teachers' perception of the activities with respect to i) Technology Acceptance Models (TAM) [24] which have been used to predict people's intent to adopt technological innovations in terms of utility, ease of use and intent to use, and ii) the Utility, Usability, Acceptability (UUA) framework [46] which has been used to evaluate teachers' perception of the use of educational robots in formal education [9, 11]. The second category concerns co-construction and translational research and focuses on the teachers' perception of : (1) the utility of parallel analysis, (2) researchers, (3) teachers' role in research, (4) co-construction in translational research.

Key quotes and syntheses from the teachers' interviews are presented in coloured boxes throughout the article to complement the analysis conducted.

\section{RESULTS AND DISCUSSION}

\subsection{The researcher-initiated case study: the robot game to teach mathematics concepts}

3.1.1 Teachers' initial perspective on the activity. The teachers felt the CSU activity provided an easy entry point to CS content (TAM, ease of use), and that it was possible to appropriate the activity and adapt it to various teaching styles (UUA, acceptability). Both teachers attributed an importance to the link with other activities in the curriculum that address spatial skills, as it 1) helps alleviate time constraints, a critical factor limiting curricular innovation and the adoption of new pedagogical content $[11,17,18]$ and 2) offers a kinaesthetic way of addressing spatial skills compared to more traditional alternatives (UUA, usability).

Concerning student learning, the teachers found the activity useful (utility, UUA and TAM) at multiple levels. In addition to fostering spatial abilities and working on relative and absolute positioning, the activity can be leveraged to foster transversal skills. As the grade 4 teacher mentioned, the activity pushes students to adopt different roles (thus seeing different perspectives), verbalise, provide constructive feedback to one another etc..., all key benefits of kinaesthetic learning which differ from traditional paper-based maths activities. The grade 3 teacher did however express that the activity might not differ much in terms of transversal skills compared to other kinaesthetic activities already in the curriculum.

Finally, the interviews highlighted that the CSU activity was considered as age appropriate (usability, UUA). The teachers mentioned that sessions with half of the class (or another teacher) facilitated classroom management and ensured that all students participated equally [43]. One teacher believed the activity should be conducted in multiple smaller sessions over a longer period of time, so that all the students have time to assimilate the concepts. The teachers believed the CSU activity (and other CS activities that employ different instruction modalities, e.g. robotics unplugged activities with the Bluebot [17]) is a good means of introducing grid-related concepts.

For these reasons, the teachers expressed their intent to continue to introduce the content in the future (TAM, intent) and to appropriate it (UUA, acceptability).

Synthesis of the teachers' initial perspective : the robot game

- Is an easy entry point for teachers to teach CS (ease of use)

- Can be adapted to various teaching styles (acceptability)

- Has strong links with maths and spatial abilities (utility)

- Is kinaesthetic (usability) and fosters transversal skills (utility)

- Teachers intend to adopt (intent) and appropriate the activity (acceptability)

3.1.2 Student learning. Students' learning was assessed by the researcher using the pre-post test and criteria described in section 2.1.3. Prior to presenting the criteria employed for the analysis, we asked the teachers which metrics they believed were most relevant. A comparison between the teachers' and researchers' metrics helped establish that they were well aligned, with the teachers adding that they believed the researchers' metrics were complete. Using a relative grading approach on the two main criteria (abstraction of the grid, path coding strategy) from the pre-test, three groups of students of same size were established :

(1) G0 with the lowest initial scores,

(2) G1 with intermediate initial scores,

(3) G2 with the highest initial scores.

According to the teachers, aside a couple of cases (3 exceptions out of 22 in grade 3, 1 out of 21 in grade 4 ), these groups were in line with the maths levels of the students at the time of the pre-test was conducted.

Fig. 5 shows the distribution of students' pre-post test scores according to the relative ranking on the pre-test and the grade. Overall, Wilcoxon's signed-rank test shows that students in G0 improved ( $Z=10, p=0.023$, Cohen's $D=1.04$ ) by $32 \%$, while students in G1 maintained their level $(p>0.05)$, and students in $\mathrm{G} 2$ decreased ( $Z=15, p=0.0035$, Cohen's $D=0.48$ ) by $10 \%$ (see Fig. 5). A qualitative analysis by grade helps gain insight into 

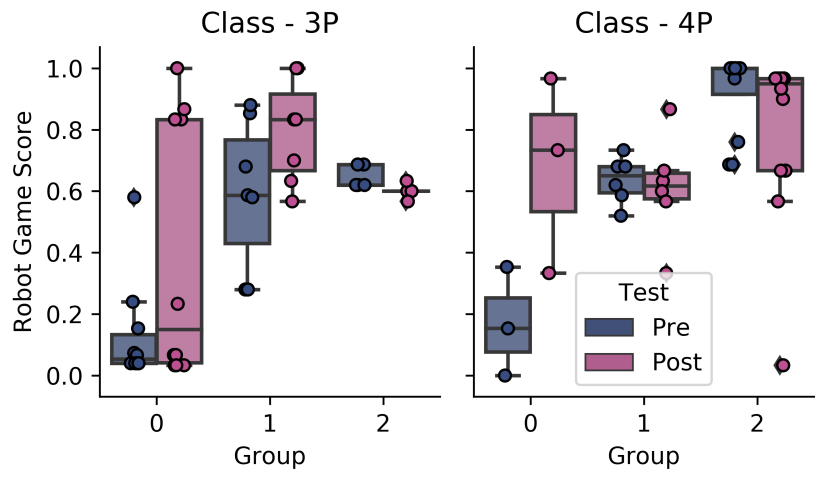

Figure 5: The robot game pre-post test score distribution considering the sum of the normalised scores for abstraction of the grid, path coding strategy, notion of sequence, and of distance. The total is normalised between $0(\mathrm{~min})$ and 1 (max).

these results. Students in G0 exhibited two distinct behaviour. While some progressed significantly, some appeared to be stuck, notably in grade 3 . The grade 3 teacher believed this was because it was too soon to introduce these concepts for some students in G0, who still had other notions to assimilate before addressing the grid-related concepts. At the other end, the students in G2, irrespective of grade, appeared to have had a good initial strategy which they did not change with the activity, therefore exhibiting little to no progress. Students in G1, on the other hand, were likely less confident in their initial solutions and tried to improve on it, with many varying on their initial approach. While students in grade 4-G1 did not progress, there was a marked progress for those in grade $3-\mathrm{G} 1$.

With respect to the individual metrics, we focus here on the abstraction of the grid and the coding strategies as they are the concepts which required the highest level of abstraction and are thus the most complex to address. While students altered their solutions in terms of abstraction of the grid when they did not have a good initial strategy, this was not necessarily the case for the coding strategy. Whenever the students had a relatively "satisfactory" initial coding strategy, they tended to maintain it, despite having been introduced to other alternatives during the sessions. Both teachers reported the need for specific teachers interventions to push the students to question themselves and look for new solutions, both during the tests and the activity. Indeed, it appears common for students to stick to a strategy and not change it unless prompted [43]. Globally, the results were not only deemed coherent by the teachers with their knowledge of the students and their prior abilities, but also with their participation in the activities themselves, as well as their progress in other contexts.

When considering the progress made by the students on the pre-post test (using the normalised change [35]), the teachers offered interesting insight into the results. In grade 3, the teacher stated that the students that maintained their level were those who tended to be less confident, more afraid to try things out on their own and of making mistakes, and who often looked to the teacher for support. On the other hand, the same teacher mentioned that those who progressed the most were the students who struggled in the beginning of the year and made considerable progress both in maths and all around.

\subsection{The teacher-initiated case study: the sorting machine to teach spelling}

3.2.1 Teachers' initial perspective on the activity. Similarly to the robot game, the sorting machine is perceived as an easy introduction to CS-type activities (TAM, ease of use) as it is not very time consuming and can easily be adapted to various teaching styles (UUA, acceptability), in line with the need to "create lesson frameworks that are easily usable, and modifiable by teachers to work within their classrooms" [32]. There were however certain limitations due to the structure of the sorting machine which required sorting 6 objects. While the teachers innovated by grouping certain letters together to adapt to longer words, this was considered to be quite constraining, with the need for easily modifiable material being of relevance [32].

The teachers perceived the sorting machine as an interesting approach to spelling that they believed could complement other traditional approaches (utility, UUA and TAM, see section 2.2.1). They believed that numerous transversal skills were at play (in the teachers' words: collaboration, autonomy, patience, discussion, not being afraid to try again and start over, being more accepting of criticism and errors). However, beyond the transversal skills, the teachers looked over the pre-post tests to determine whether major spelling difficulties had been addressed. Their initial assessment did not clearly identify benefits in terms of learning, putting into question their initial hypothesis about the utility of such an activity to practice spelling.

In terms of usability (UUA), contrary to the robot game, the teacher believed that the sorting machine may require starting with an easy activity with numbers to first grasp the mechanisms of the sorting machine and underlying CS concepts before being able to focus on practising spelling. Indeed, once the students understood the underlying mechanisms they remembered the activity quite well. Similarly to the robot game however, the teachers expressed difficulties in terms of classroom management with the need to have multiple teachers, splitting the class in two, or having multiple sessions with smaller groups, or split the class in two [43].

Synthesis of the the teachers' initial perspective : the sorting machine

- Is an easy entry point for teachers to teach CS (ease of use),

- Can be easily adapted to various teaching styles (acceptability),

- Needs to be preceded by CS session with numbers so students first grasp the underlying mechanisms before sorting any other entity (usability) 
- Is kinaesthetic (usability) and fosters transversal skills (utility)

- Can complement other traditional means of teaching spelling (utility)

- Teachers intend to adopt (intent) and appropriate the activity (acceptability)

3.2.2 Student learning. The results based on the normalised change [35] for each word and student showed an average improvement of $22 \%$ ( $4 \%$ standard error of the mean) which was more than what the teachers expected after their initial assessment of the pre-post tests, thus confirming for them that there is value in doing the activity as one means to practice spelling. No significant differences were found between students in grades 3 and 4, which the teacher mentioned was not surprising as just one year separated them. As Fig. 6 shows, some words were initially harder for the students ("emballer", "jouets" et "bonnet"). Interestingly, the pre-post test results showed that students improved significantly for the two words with double consonants (Wilcoxon signed-rank test for related samples, "bonnet" $Z=7.5, p=0.040$; "emballer" $Z=12, p=0.0057$ ). When considering the results per student, 6 students (out of the 22 who were present for both the pre- and post-tests) made more errors in the post-test than in the pre-test, according to the 75th percentile. Interestingly, these students were all native French speakers, with the three non-native French speakers having improved on their spelling.

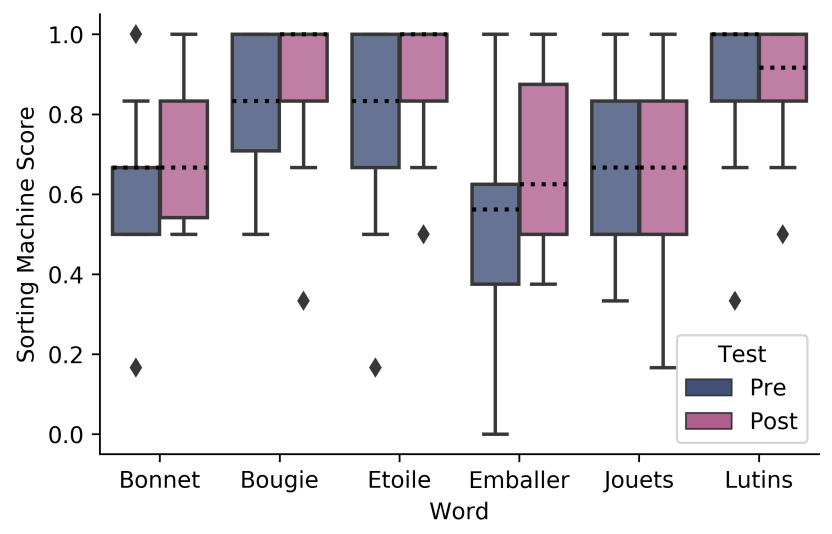

Figure 6: The sorting machine french spelling pre- and posttest score distribution between 0 ( $\mathrm{min}$, all wrong) and $\mathbf{1}$ (max, all right) based on the normalised Levenshtein distance.

The interview with the teacher who initiated the study highlighted the fact that students' performance on spelling is often dependent on their concentration, both during the activity and the test. Therefore, and contrary to the assessment of maths concepts, the reliability of a pre-post spelling test is relatively low, with many external factors to take into account, suggesting the need to observe progress over a longer time frame.

\subsection{Reflections on co-construction}

3.3.1 Perceived utility of the parallel analysis. The researchers believe the teachers' perspective provided meaningful insight and depth to the analysis of student learning, an opinion that was mirrored by the teachers. The latter found both the second point of view and the scientific method useful as it was devoid of impressions and went beyond a priori. Studies have indeed shown that biases are prominent in school settings, even when tasks and grades are assigned to students [33]. In particular, teachers believed the quantification of progress and the added visualisations helped identify what was useful and what wasn't.

[Grade 4 teacher] "Research shows concrete evidence of progress and helps identify what is useful. [...] It helps validate or not the intuitions. You don't always know if you're right or not. It's good to have an outside perspective. [...] In the end, the aim is to see how useful and interesting it is for the students. Research allows us to have an outside view, not just that of the teachers. It allows us to have another vision of our profession and the activity we do, to question ourselves and see how to improve it."

While the teachers expressed not having time to do similar analyses themselves, they were interested in having them more frequently.

[Grade 3 teacher] "It would be interesting to have these analyses more regularly, but it is a matter of time."

[Grade 4 teacher] "We don't have time, we don't do graphs. Seeing them allows us to see the improvements and progress. I'd be interested in having analyses like this more regularly. It helps understand what's happening in general, and to see what really works and what doesn't."

It would therefore appear that researchers and teachers stand to benefit from joint analyses, notably when considering that i) teachers don't have time to dedicate to in depth analyses, often focusing more on preparation of activities and classroom management than the validation of student learning [27] and ii) researchers would gain a deeper and broader understanding of student learning, which allows to better design and assess learning activities.

3.3.2 Teachers' perception of researchers. The teachers did not have prior experience with research and had preconceptions about researchers that were in line with many stereotypes such as not knowing the field, not understanding students, lack of flexibility etc..., sentiments often echoed by K-12 teachers [29].

[Grade 3 teacher] "I had preconceived ideas that didn't correspond to how things went in our case. For example, that researchers don't know the children, or the daily life of a classroom. Or that researchers are not necessarily interested in the children and do not consider what is going outside the experiment itself, in the daily life of the class. There is often this image of the researcher who has not seen a child." 
[Grade 4 teacher] "I used to have the impression that the researchers had their objectives and that was it. They just had to write their report."

The teachers' perspective changed after participating in the research, notably after grasping the importance of conducting translational research in the field in the most "natural" settings for the students and as close as possible to the way teachers normally teach.

[Grade 3 teacher] "It was interesting to have the research in the field, to have the researcher present to make the observations, instead of just giving the procedure and leaving us to do it alone. [...] I understood later that the aim was for the activities to be carried out as usual."

While it is true that research has requirements which often involve sticking to a specific methodology, it is important to consider how translational research is conducted in classrooms, which has an impact on the quality of co-construction [44]. In particular, it is important to keep in mind that the paradigm of going into classrooms, asking for things unrelated to teachers' teaching, and going back out tends to foster such negative sentiments [29] and thus negatively impacts the prospects of translational research, such as school-university partnerships [44]. Co-construction appears to help address such biases which are frequent barriers to translational research in education, as shown by the teachers' change in perspective about researchers in the present study. That is why we believe co-construction should be favoured by researchers looking to conduct translational research.

[Grade 4 teacher] "Whether it's you or the other researchers [of the centre involved in the digital education reform], you are motivating and make people want to do things. We see that you are ready to modify, to change according to what you see in the field. You left me free to approach the activities as I wanted, and to be close to the reality of the field. I have a different view of researchers following these experiences, also by seeing the human side that you have, the fact that you are understanding, accommodating. [...] I appreciated the informal exchanges. That's also why I want to continue, and to invest myself and do what I can."

However, it is not just teachers that have biases about researchers, but researchers as well, both about teachers [29] and themselves. The literature on university-school partnerships has often evoked the presence of a power struggle [29], where it is important to consider that teachers have expertise in the classroom that researchers usually lack, and to value all stakeholders for their expertise. Only then will it be possible to establish effective dialogues, meaningful interactions and shared understanding which are "enabling factors that determine successful co-creation" [30].
3.3.3 Teachers' perception of their role in research. The teachers evoked that their role was not very clear at the start of the interactions, and required being willing to accept having somebody come in and observe.

[Grade 3 Teacher] "I wasn't quite sure where things were going at the beginning. The objectives weren't very clear. It wasn't clear who was going to do the activities. I thought it would be the researchers to avoid biases. I was also trying to stick to the activity guidelines a bit too much. I understood later that the aim was for the activities to be carried out as usual. But it's still destabilising to have someone coming in and observing."

As co-construction involves collaboration between people from different backgrounds, one must be able to manage a certain level of uncertainty, and be willing to invest the time to go beyond their comfort zone [44] to familiarise with one another, understand the others' expertise and create a level of shared understanding. Interestingly, the way co-construction is approached affects the teachers' perception of their role and expertise in the process. In the researcher-initiated case study, the teachers felt more like an "aid", rather than an invested party that can reflect on the protocol and assessments to be done as the teachers did in the teacher-initiated case study.

[Grade 4 teacher] "I had less expectations for the [researcherled study (the robot game)] than the [teacher-led study (the sorting machine)] because I was not the one who created the project. I felt a bit more like an aid and was a bit less active."

We must therefore consider the implication of these different ways of establishing co-construction and the relationship. Indeed, previous studies in the context of co-design of lessons have shown the importance of agency [23] and creating a sense of ownership $[22,23,27]$, which ultimately contribute to an increased likeliness of adoption [28] of innovation. In particular, a comparison of three case studies [23] shows the benefits of co-design which includes a good equilibrium between cooperation (i.e. where labour is divided) and collaboration (i.e. a "[mutual engagement] in a coordinated effort to solve the problem") [15] throughout the various phases of the project. Thus, to effectively co-construct, it would appear that an optimum between collaboration and cooperation must be reached. Therefore, beyond understanding each others' profession, strengths and competencies, an awareness of the complementarity and what each stands to gain from co-construction is likely key, with the co-construction modality playing a role in the outcome.

3.3.4 Teachers' perspective on translational research and coconstruction. From the interviews, co-construction for translational research, in addition to being "rewarding" to contribute to, appears as a trigger of "innovation", "change" and "progress", inciting the teachers to do things differently and encouraging them to collaborate on various endeavours. 
[Grade 3 teacher] "Doing research in the classroom pushes one to do more. I enjoyed having another perspective, it pushed me to do other things, to innovate, especially considering that it's easy to continue to do the same things over and over."

[Grade 4 teacher] "You see the value of research when you are involved in it. It's rewarding to be part of the evolution of digital education and to be part of the research. Participating in research allows me to see new things and to approach my teaching differently, for example by doing a small test at the beginning, a small test at the end"

By introducing new approaches, one teacher even expressed a change in their personal manner of answering a question and introducing changes to their teaching, for example understanding the need for small incremental changes, i.e. to "change things little by little instead of revolutionising everything as I would normally want to do" [Grade 4 teacher], with validation in order to draw meaningful conclusions. Concrete examples from the case studies and interviews include leading the teacher driven case study, and suggesting a prior analysis of pre-tests in the robot game case study to adapt their teaching accordingly. However the teacher also mentioned it was not always easy to know how to go about doing these changes. This is coherent with the fact that university is no longer considered a place for "one off training" with an increasing need for "lifelong learning [which] urges teachers, educators and academics to reconceptualise and transform education" [36] through collaborations and school-university partnerships which are "important for professional development and educational reform" [36]. It would therefore appear that teachers and researchers can draw from each other's expertise to adjust their strategies within the context of educational reform.

\section{CONCLUSION}

In this paper we investigated whether two CS unplugged (CSU) activities (the robot game and the sorting machine) could be introduced transversally to support other disciplines (respectively maths and spelling) in primary school (RQ1) through two case studies. To answer this question, we collaborated with teachers in a co-constructive approach to translational research (RQ3) where the teachers had the role of the experts of their classrooms (RQ2).

The findings from the mixed methods analyses, which included both the teachers' and the students' perspectives, seem to suggest that the CSU activities considered can be leveraged to teach disciplinary content (RQ1), thus abiding to constraints of time, a frequent preoccupation for teachers. We believe the depth gained from including the analysis of the students' and teachers' perspectives is beneficial and could become a more common practice in the assessment of classroom-based learning experiences. While the teachers' and researchers' perspectives were not always initially aligned (RQ2), notably in terms of expectations at the level of the paper based assessments, the combined analysis, which includes both the teachers' and researchers' perspectives (RQ2), helps construct a more comprehensive picture of the advantages and limitations of introducing the CSU activities transversally. Although promising, the findings should be validated through larger scale studies (RQ1).

Nonetheless, another key takeaway from the studies lies in the role that co-construction can play in translational research (RQ2, RQ3), and not just co-design or teacher professional development as it more commonly appears in the literature. Just as the teachers' perspective adds depth to the research by providing complementary expertise into the classroom, the research methodology offers a perspective which the teachers appreciated as it is devoid of biases and impressions, an identified limitation of classroom assessments. By building a more complete picture into the potential of the CSU activities with respect to student learning, both teachers and researchers can adjust their practice accordingly.

The benefits of co-construction would also appear to extend beyond the research itself (RQ3). Indeed, the interviews highlighted that biases can be positively addressed through co-construction. Teachers and researchers should value each others' expertise [44] and strive to reach a level of mutual understanding in which coconstruction, from which both can mutually benefit, may occur. While both cases of co-construction helped pave the way for future research collaborations, the interviews showed that the modality in which co-construction occurred had an influence on the teachers' sense of ownership. Future work should therefore investigate the effect of different co-construction modalities in translational research, notably provided the role co-construction may play as a trigger for innovation and change of practices in $\mathrm{K}-12$, for both teachers and researchers. Lastly, while the present work only interviewed teachers, future work will explore co-construction and its effects for all parties involved in CS curricular reform, including researchers.

\section{ACKNOWLEDGMENTS}

We would like to thank the NCCR Robotics Switzerland for funding the project, N. Jaccard and F. Chessel-Lazzarotto for their feedback on the activity selection and student assessments, the teachers who participated in the experiments and interviews, and the students.

\section{REFERENCES}

[1] Valerie Barr and Chris Stephenson. 2011. Bringing computational thinking to $\mathrm{K}-12$ : what is Involved and what is the role of the computer science education community? Acm Inroads 2, 1 (2011), 48-54.

[2] Tim Bell, Jason Alexander, Isaac Freeman, and Mick Grimley. 2009. Computer science unplugged: school students doing real computing without computers. New Zealand Journal of Applied Computing and Information Technology 13, 1 (2009), 20-29.

[3] Tim Bell and Jan Vahrenhold. 2018. CS Unplugged-How Is It Used, and Does It Work? In Adventures Between Lower Bounds and Higher Altitudes. Springer, Cham, 497-521.

[4] Jérôme Brender, Laila El-Hamamsy, Barbara Bruno, Frédérique ChesselLazzarotto, Jessica Dehler Zufferey, and Francesco Mondada. 2021. Investigating the Role of Educational Robotics in Formal Mathematics Education: The Case of Geometry for 15-Year-Old Students. In Technology-Enhanced Learning for a Free, Safe, and Sustainable World (Lecture Notes in Computer Science). Springer International Publishing, Cham, 67-81.

[5] Tereza Cahlikova. 2020. The implementation of a digital curriculum on the local level: lessons from a Swiss case study. In Proc. 13th International Conference on Theory and Practice of Electronic Governance. ACM, 184-191.

[6] Tereza Cahlikova and Pirmin Bundi. 2020. Managing the Rise of the Digital State: Implementation of Digital Education by Local Government. Fahrbuch der 
Schweizerischen Verwaltungswissenschaften 11, 1 (2020), 145-157.

[7] Luis Alberto Calao, J. Moreno-León, Heidy Ester Correa, and Gregorio Robles. 2015. Developing Mathematical Thinking with Scratch. In Design for Teaching and Learning in a Networked World. Springer, Cham, 17-27.

[8] Veronica Cateté, Amy Isvik, and Tiffany Barnes. 2020. Infusing Computing: A Scaffolding and Teacher Accessibility Analysis of Computing Lessons Designed by Novices. In Proceedings of the 20th Koli Calling International Conference on Computing Education Research. ACM, 1-11.

[9] Morgane Chevalier, Laila El-Hamamsy, Christian Giang, Barbara Bruno, and Francesco Mondada. 2022. Teachers' Perspective on Fostering Computational Thinking Through Educational Robotics. In Robotics in Education (Advances in Intelligent Systems and Computing). Springer International Publishing, Cham, 177-185.

[10] Morgane Chevalier, Christian Giang, Alberto Piatti, and Francesco Mondada 2020. Fostering computational thinking through educational robotics: a model for creative computational problem solving. If STEM Ed 7, 1 (2020), 39.

[11] Morgane Chevalier, Fanny Riedo, and Francesco Mondada. 2016. Pedagogical uses of thymio II: How do teachers perceive educational robots in formal education? IEEE Robot Autom Mag 23, 2 (2016), 16-23.

[12] Merijke Coenraad, Jen Palmer, Donna Eatinger, David Weintrop, and Diana Franklin. 2021. Using participatory design to integrate stakeholder voices in the creation of a culturally relevant computing curriculum. Int. f. Child-Comput. Interact. (July 2021), 100353.

[13] Valentina Dagiene and Gabriele Stupuriene. 2016. Informatics concepts and computational thinking in K-12 education: A Lithuanian perspective. fournal of Information Processing 24, 4 (2016), 732-739.

[14] Elizabeth A. Davis, Carrie Beyer, Cory T. Forbes, and Shawn Stevens. 2011. Understanding pedagogical design capacity through teachers' narratives. Teaching and Teacher Education 27, 4 (2011), 797-810.

[15] Pierre Dillenbourg, Michael J. Baker, Agnès Blaye, and Claire O’Malley. 1995. The evolution of research on collaborative learning. In Learning in Humans and Machine: Towards an interdisciplinary learning science., Spada, E., Reiman, and P. (Eds.). Elsevier, Oxford, 189-211.

[16] Laila El-Hamamsy, Barbara Bruno, Frédérique Chessel-Lazzarotto, Morgane Chevalier, Didier Roy, Jessica Dehler Zufferey, and Francesco Mondada. 2021 The symbiotic relationship between educational robotics and computer science in formal education. Educ Inf Technol 26, 5 (Sept. 2021), 5077-5107.

[17] Laila El-Hamamsy, Frédérique Chessel-Lazzarotto, Barbara Bruno, Didier Roy, Tereza Cahlikova, Morgane Chevalier, Gabriel Parriaux, Jean-Philippe Pellet, Jacques Lanarès, Jessica Dehler Zufferey, and Francesco Mondada. 2021. A computer science and robotics integration model for primary school: evaluation of a large-scale in-service K-4 teacher-training program. Educ Inf Technol 26, 3 (May 2021), 2445-2475.

[18] Peggy A. Ertmer. 1999. Addressing first- and second-order barriers to change: Strategies for technology integration. Educ. Technol. Res. Dev. 47, 4 (1999), 47-61.

[19] European Union and Audiovisual and Culture Executive Agency Education. 2019 Digital education at school in Europe. Publications Office of the European Union, Brussels.

[20] Robin Jocius, Deepti Joshi, Yihuan Dong, Richard Robinson, Veronica Cateté, Tiffany Barnes, Jennifer Albert, Ashley Andrews, and Nicholas Lytle. 2020. Code, Connect, Create: The 3C Professional Development Model to Support Computational Thinking Infusion. In Proc. 51st ACM Tech. Symp. Comput. Sci. Educ. 971-977.

[21] Sarah-Louise Jones, Richard Procter, and Sarah Younie. 2015. Participatory knowledge mobilisation: an emerging model for international translational research in education. Fournal of Education for Teaching 41, 5 (Oct. 2015).

[22] Herma Jonker, Virginie März, and Joke Voogt. 2019. Collaboration in teacher design teams: Untangling the relationship between experiences of the collaboration process and perceptions of the redesigned curriculum. Stud. Educ. Evaluation 61 (2019), 138-149.

[23] Jacob Kelter, Amanda Peel, Connor Bain, Gabriella Anton, Sugat Dabholkar, Michael S. Horn, and Uri Wilensky. 2021. Constructionist co-design: A dual approach to curriculum and professional development. Br F Educ Technol (2021).

[24] William R. King and Jun He. 2006. A meta-analysis of the technology acceptance model. Information \& Management 43, 6 (2006), 740-755.

[25] Janika Leoste and Mati Heidmets. 2020. Bringing an Educational Robot into a Basic Education Math Lesson. In Robotics in Education (Advances in Intelligent Systems and Computing). Springer, Cham, 237-247.

[26] Janika Leoste, Mati Heidmets, and Tobias Ley. 2021. What Makes New Technology Sustainable in the Classroom: Two Innovation Models Considered. In Ludic, Codesign and Tools Supporting Smart Learning Ecosystems and Smart Education (Smart Innov. Syst. Technol.). Springer, 53-65.

[27] Janika Leoste, Kairit Tammets, and Tobias Ley. 2019. Co-Creation of Learning Designs: Analyzing Knowledge Appropriation in Teacher Training Programs. In Companion Proceeding of the 14th European Conference on Technology-enhanced Learning (EC-TEL). 9.

[28] Janika Leoste, Kairit Tammets, and Tobias Ley. 2020. Co-Creating Learning Designs in Professional Teacher Education: Knowledge Appropriation in the
Teacher's Innovation Laboratory. Interaction Design and Architecture(s) 42 (Jan. 2020), 131-163.

[29] Mitzi Lewison and Sue Holliday. 1997. Control, Trust, and Rethinking Traditional Roles: Critical Elements in Creating a Mutually Beneficial University-School Partnership. Teacher Education Quarterly 24, 1 (1997), 105-126.

[30] Tobias Ley, Janika Leoste, Katrin Poom-Valickis, María Rodríguez-Triana, Denis Gillet, and Terje Väljataga. 2018. Analyzing Co-Creation in Educational Living Labs using the Knowledge Appropriation Model. In Workshop on Co-Creation in the Design, Development and Implementation of Technology-Enhanced Learning (CC-TEL'18).

[31] Nicholas Lytle, Veronica Cateté, Danielle Boulden, Yihuan Dong, Jennifer Houchins, Alexandra Milliken, Amy Isvik, Dolly Bounajim, Eric Wiebe, and Tiffany Barnes. 2019. Use, Modify, Create: Comparing Computational Thinking Lesson Progressions for STEM Classes. In Proc. Annu. Conf. Innov. Technol. Comput. Sci. Educ. ITiCSE (2019). ACM, 395-401.

[32] Nicholas Alan Lytle and others. 2020. Strategies for Designing, Scaffolding, and Leading Open-Ended Programming Projects within Core K-12 Classrooms. Ph. D. Dissertation.

[33] John M Malouff and Einar B Thorsteinsson. 2016. Bias in grading: A meta-analysis of experimental research findings. Aust. F. Educ. 60, 3 (2016), 245-256.

[34] Linda Mannila, Valentina Dagiene, Barbara Demo, Natasa Grgurina, Claudio Mirolo, Lennart Rolandsson, and Amber Settle. 2014. Computational Thinking in K-9 Education. In Proceedings of the Working Group Reports of the 2014 on Innovation \& Technology in Computer Science Education Conference (ITiCSE-WGR '14). Association for Computing Machinery, Uppsala, Sweden, 1-29.

[35] Jeffrey D. Marx and Karen Cummings. 2006. Normalized change. American Fournal of Physics 75, 1 (2006), 87-91.

[36] Sharon S.N. Ng and Esther Y.M. Chan. 2012. School-University Partnership: Challenges and Visions in the New Decade. Global Studies of Childhood 2, 1 (2012), 38-56. Publisher: SAGE Publications.

[37] Amanda Peel, Sugat Dabholkar, Gabriella Anton, Sally Wu, Uri Wilensky, and Michael Horn. 2020. A Case Study of Teacher Professional Growth Through Co-design and Implementation of Computationally Enriched Biology Units. In The Interdisciplinarity of the Learning Sciences, Vol. 4. 1950-1957.

[38] Amanda Peel, Troy D. Sadler, and Patricia Friedrichsen. 2021. Using Unplugged Computational Thinking to Scaffold Natural Selection Learning. The American Biology Teacher 83, 2 (2021), 112-117.

[39] Marine Roche. 2019. L'acceptation d'un nouvel enseignement à l'école primaire: les professeurs des écoles face à la programmation informatique. Ph. D. Dissertation. Nantes.

[40] Margarida Romero, Marie Duflot-Kremer, and Thierry Viéville. 2018. Le jeu du robot : analyse d'une activité d'informatique débranchée sous la perspective de la cognition incarnée. Review of science, mathematics and ICT education (2018). Publisher: Laboratory of Didactics of Sciences, Mathematics and ICT, Department of Educational Sciences and Early Childhood Education - University of Patras..

[41] Audrey Rorrer, David Pugalee, Callie Edwards, Danielle Boulden, Mary Lou Maher, Lijuan Cao, Mohsen Dorodchi, Veronica Catete, David Frye, Tiffany Barnes, and Eric Wiebe. 2021. The Design and Implementation of a Method for Evaluating and Building Research Practice Partnerships. In Proc. 52nd ACM Tech. Symp. Comput. Sci. Educ. 753-759.

[42] Marina Rottenhofer, Barbara Sabitzer, and Tom Rankin. 2021. Developing Computational Thinking Skills Through Modeling in Language Lessons. Open Education Studies 3 (2021), 17-25.

[43] Sina Shahmoradi, Aditi Kothiyal, Jennifer K. Olsen, Barbara Bruno, and Pierre Dillenbourg. 2020. What Teachers Need for Orchestrating Robotic Classrooms. In Addressing Global Challenges and Quality Education (LNCS). Springer, Cham, 87-101.

[44] Karl Smith. 2016. Partnerships in teacher education-going beyond the rhetoric, with reference to the Norwegian context. ceps fournal 6, 3 (2016), 17-36.

[45] The Royal Society. 2017. After the reboot: computing education in UK schools. OCLC: 1079199842

[46] A Tricot, F Plégat-Soutjis, J Camps, A Amiel, G Lutz, and A Morcillo. 2003. Utility, usability, acceptability: interpreting the links between three dimensions of the evaluation of the computerized environments for human training (CEHT). Environnements Informatiques pour l'Apprentissage Humain (2003).

[47] Mary Webb, Niki Davis, Tim Bell, Yaacov J Katz, Nicholas Reynolds, Dianne P Chambers, and Maciej M Sysło. 2017. Computer science in K-12 school curricula of the 2lst century: Why, what and when? Educ Inf Technol 22, 2 (2017), 445-468.

[48] David Weintrop. 2016. Defining Computational Thinking for Mathematics and Science Classrooms. I Sci Educ Technol (2016), 21.

[49] S. Wu, A. Peel, C. Bain, G. Anton, M. Horn, and U. Wilensky. 2020. Workshops and Co-design Can Help Teachers Integrate Computational Thinking into Their K-12 STEM Classes. Proc. Int. Conf. on Computational Thinking Education (2020).

[50] Yuqin Yang, Yanwen Long, Daner Sun, Jan Van Aalst, and Sanyin Cheng. 2020. Fostering students' creativity via educational robotics: An investigation of teachers' pedagogical practices based on teacher interviews. Br f Educ Technol 51, 5 (2020), 1826-1842. 